\title{
Characterising the alternative and polar questions of Irish
}

\author{
Brian Nolan \\ Technological University Dublin, Ireland
}

\begin{abstract}
This paper gives an account of the similarities and differences between alternative and polar questions, where these question forms stand at the intersection of syntax, semantics, and pragmatics. We contrastively examine the nature of alternative and polar yes-no questions. We characterise the forms of these question types and the functions they serve. We examine the semantic and pragmatic dimensions of each question form and their answers. We characterise the felicity conditions necessary for their successful realisation of the speech act of requesting information via the alternative and yes-no interrogatives and assume that information is freely exchanged under a Gricean presumption of cooperation. We show that alternative questions have some similarities, but also significant differences, to polar yes-no questions. Alternative questions do not allow for yes-no answers. Instead, an appropriate answer must contain one of a selection from the alternative choice options listed in the framing of the question. Alternative questions are dependent on the presence of disjunction. We characterise the syntax and semantics of polar yes-no questions. We demonstrate in respect of the answers to polar yes-no questions of Irish that they contain instances of ellipsis and are full clausal expressions with a complete semantics where the elided elements are from the question part of the question-answer pair. The propositional content of polar yes-no questions is inferred from the context, specifically from the question with which the answer is paired. Irish does not have any exact words which directly correspond to English 'yes' or 'no' and so employs different strategies where a yes-no answer is required.
\end{abstract}

\section{Introduction}

This paper ${ }^{1}$ compares and contrasts the syntactic forms of alternative questions with those of polar questions and how these question types differ in function, as instances of the speech act of requesting information. We characterise the syntax, functions, and pragmatics of alternate questions and polar yes-no interrogatives as question-answer pairs. We consider the felicity conditions necessary for the speech act interaction to be successfully realised. We assume that information is freely exchanged under a Gricean presumption of cooperation (Grice 1957, 1969, 1986). Irish uses a variety of syntactically significant question particles in the formation of its different question forms. From Dryer (2005: 470), we know that question particles are common

1 I wish to thank the two reviewers for their useful and helpful comments. The paper has benefited from these points raised. 
in the world's languages as a cue in the syntactic structure of interrogatives. We examine the features of these in their morphosyntactic context. Other elements of the grammar of Irish have been reported on in Nolan $(2008,2012,2013,2014,2017,2019)$. We argue that a core function of interrogatives is the maintenance of common ground between the interlocutors. The construction and maintenance of common ground is crucial to retrieving meaning.

It is, of course, natural and normal during our discourses to seek information from our conversational partner. The canonical function of the interrogative is to seek information. Languages have different strategies for soliciting different kinds of information, and Irish is no different in this regard. Typically, these questioning strategies require sentences with different structural forms to act as signalling cues for the various kinds of information required (Nolan 2019:105-136). The use of questions and answers is therefore central within dialogue in language (Coulthard 1992, Dayal 2018, Dryer 2005, Hamblin 1973, Holmberg 2015).

Specifically, then, this paper gives an account of the differences between alternative and polar questions, where these question forms stand at the intersection of syntax, semantics, and pragmatics. The primary function of interrogatives is the maintenance of information in common ground via the update and exchange of information between the interlocutors. In this paper, we contrastively examine the nature of alternative and polar yes-no questions. We characterise the forms of these question types and the functions they serve, touching upon semantic and pragmatic dimensions of each question form and their answers. We characterise the felicity conditions necessary for the successful realisation of the speech act of requesting information via the alternative and yes-no interrogatives, and assume that information is freely exchanged under a Gricean presumption of cooperation.

We show that alternative questions have some similarities, but also significant differences, to polar yes-no questions. Alternative questions do not allow for yes-no answers. Instead, an appropriate answer must contain one of a selection from the alternative choice options listed in the framing of the question. Alternative questions are dependent on the presence of disjunction.

We demonstrate in respect of the answers to polar yes-no questions of Irish that they contain instances of ellipsis and are full clausal expressions with a complete semantics where the elided elements are from the question part of the question-answer pair. The propositional content is inferred from the context, specifically from the question with which the answer is paired. Irish does not have any exact words which directly correspond to English 'yes' or 'no' and so employs different strategies where a yes-no answer is required. The fact that languages have clausal types for asking questions shows clearly how important this activity is to human communication, and the construction and maintenance of shared common ground.

The paper has the following organisation. Section 2 examines the nature of the speech act of requesting information and outlines the felicity conditions necessary for a successful, i.e., felicitous, act of questioning. We note the important role of context in the meaning of these speech acts. In section 3 we examine Irish alternative questions while in Section 4 we explore the polar yes-no question form of Irish. Section 4 explores the nature of the answers to these question types, highlighting the main strategy used, the verb-echo strategy, when there are no direct words for 'yes' or 'no' in the language. We characterise the important features of the answers to the questions. Section 5 draws a number of conclusions and reviews similarities and differences between Irish alternative questions and polar questions. 


\section{Context and the speech act of requesting information}

Interrogative sentences are associated with the speech act of requesting information via questioning. Interrogative sentences fall into three major classes depending on their syntactic and semantic properties. The required response to one of these question forms may be constrained in certain ways, depending on the nature of the question (1).

(1) Types of questions

a. Alternative questions expect an answer based on one of the options presented within the question.

b. Polar yes-no questions expect affirmation or negation as an answer.

c. Information questions (WH-questions) typically expect an answer from an open set of possible replies, where the wh-word serves to target a specific information gap. ${ }^{2}$

In order to ask a question as a speech act, certain things must be appropriate in the context in which the speech act is uttered. In other words, a sentence must not only be grammatical to be correctly performed, it must also be felicitous. A central assumption is that the Gricean Cooperative Principle (Grice 1957, 1969, 1986) and its associated maxims apply. The Gricean Cooperative Principle Maxims are i) Quality: Speakers' contributions should be true; ii) Quantity: Speakers' contributions should be only as informative as the situation requires and speakers should refrain from saying either too little or too much; iii) Relevance: Contributions should relate to the purpose of the exchange; iv) Manner: Contributions should avoid obscurity and ambiguity and be clear, orderly and succinct. The speech act formalisation concerns the objective conditions of satisfaction for the speech act and its utterance meaning. In the discourse chain, the hearer's response to the question depends on whether the hearer believes that the speaker is obeying Grice's maxim of quality. If the hearer believes that the speaker is obeying the maxim of quality in asking the question, then the hearer can conclude that the speaker really does not know the answer. In this case, the most cooperative response is to simply inform the speaker of the answer, replying as appropriate to the particular question form. If the hearer believes that the speaker is not obeying the maxim of quality, then the hearer can conclude that the speaker does know the answer to the question, or that an answer is not actually required. In this case, the hearer can interpret the speaker's question rhetorically, as if it were meant only to bring the answer into the discourse. Actual felicity conditions apply to the question as a speech act, and these are described (2) where $\mathrm{S}=$ speaker; $\mathrm{H}=$ hearer; and $\mathrm{p}=$ some proposition.

(2) Felicity conditions on the speech act of questioning

FELICITY CONDITIONS: QUESTION

Propositional CONTENT: Any proposition $\mathrm{p}$

PREPARATORY CONDITION: Speaker questions Hearer about proposition $\mathrm{p}$ iff

(i) $\mathrm{S}$ does not know the truth about $\mathrm{p}$.

(ii) $S$ wants to know the truth about $\mathrm{p}$.

(iii) $\mathrm{S}$ believes $\mathrm{H}$ knows the truth about $\mathrm{p}$ that $\mathrm{S}$ wants.

(iv) It is not obvious that $\mathrm{H}$ will provide the information without being asked

SINCERITY CONDITION: $\quad$ S wants this information

ESSENTIAL CONDITION: Counts as an attempt to elicit this information

2 We do not examine information questions in this paper. See Nolan (forthcoming) for discussion. 
A felicitous use of a question speech act requires that $S$ : i) not be aware of the information requested and ii) $\mathrm{S}$ believes that $\mathrm{H}$ has knowledge of that information. As part of the felicity conditions of a question, we typically presuppose ignorance, or an information gap, on the part of the speaker, and a presumption of knowledge on the part of the addressee. Of course, a speaker may already possess the relevant information but can still felicitously pose the question to an addressee (as in some examination context), if the addressee's knowledge is considered to be in doubt. An utterance is identified as an interrogative questioning form because it has a certain morphosyntactic form that provides cues (Dryer 2005: 470-473). Consequently, it has an illocutionary force that requires an answer, or some response, from the addressee.

The importance of context in assisting in the determination of speech act meaning in language has long been recognised (Malinowski 1944; Nerlich 1990; Nerlich and Clarke 1996). According to Monaghan (1979:1), an analysis of the speech act with its context of situation is core and will assist us to: "in principle account for language in its social situation, rather than as merely a collection of structural units to be analysed individually", while more recently, Stalnaker (1999) has argued for the centrality of context in speech act meaning determination, and in support of the maintenance of common ground (Kecskes and Zhang 2009). Nolan (2014) characterised the cognitive states for an actor in the dialogue (3), while Nolan (2019) proposed a model of a situation that applied to speech acts along with several important aspects of speech act characterisation (4).

(3) Cognitive states for an actor in a dialogue (Nolan 2014)

a. believe' (Actor, $\mathrm{p}$ ), has the meaning that the Actor believes that $\mathrm{p}$ is true for the Actor, where $\mathrm{P}$ is an expression in a human natural language.

b. know' (Actor, p) expresses a state of knowledge of the Actor with respect to $p$

c. want' (Actor, p) means that the Actor desires the event or state coded by p to occur.

d. intend' (Actor, p) means that the Actor intends to do p.

(4) Important aspects of speech act characterisation (Nolan 2019)

a. The set of beliefs that the Actor has at any given time;

b. The goals that the Actor will try to achieve;

c. The actions that the Actor performs and

d. The knowledge of the effects of these actions;

e. The environment information / knowledge that the Actor has (which may be incomplete or incorrect);

Context has a central role as a component of cognition in the determination of the conditions of knowledge activation as well as which elements of our knowledge apply in a given situation. Context is activated, and constructed, in the ongoing interaction as it becomes relevant, and is eventually shared by discourse interlocutors in the construction of the discourse common ground. Context includes cultural knowledge, general knowledge and shared communal beliefs, and the general experience that arises from the interplay of culture and social community. Context may also include location and environment. In determining the meaning of a speech act utterance, situational and contextual factors need to be assessed. Here we consider alternative questions and polar yes-no questions, as they are found in Irish. 


\section{The question particles}

To pose a simple alternate or yes-no question, certain question particles are used that are common to both question forms (Table 1). The forms of the question particle can vary according to the morphosyntactic context and have morphosyntactic consequences (see Table 2). On occasion, in casual speech the question particle may be omitted.

More specifically, the copula is described by Doherty (1996:11) as an inflectional particle that has a paradigm for combination with various 'presentential particles' (5). Advancing our understanding of how copula sentences relate to verbal sentences, Ó Sé (1990:2-4) considers how various verbal grammatical categories are represented in the Irish copula, with only two basic forms of the copula occurring in Modern Irish, is and $b a$, that fuse with negative and interrogative particles. Linguists are not yet in agreement regarding the status of the Modern Irish copula and its character.

(5)

$$
\begin{aligned}
& \text { interrogative }+ \text { copula } \\
& \text { negation }+ \text { copula } \\
& \text { subordination }+ \text { copula }
\end{aligned}
$$

\begin{tabular}{|c|c|c|c|}
\hline \multirow[t]{2}{*}{$\begin{array}{l}\text { present } \\
\text { tense }\end{array}$} & affirmative: & $\begin{array}{l}\text { An }+ \text { verb }+ \text { subject }+ \text { object }_{1}+\text { object }_{2} \\
\text { An ólann tú fuisce nó caife? } \\
\text { Do you drink whiskey or coffee? }\end{array}$ & Alternative question \\
\hline & negative & $\begin{array}{l}\text { Nach + verb + subject + object } \\
\text { Nach n-ólann tú fuisce? } \\
\text { Don't you drink whiskey? }\end{array}$ & Polar question \\
\hline \multirow[t]{2}{*}{$\begin{array}{l}\text { past/preterit } \\
\text { tense }\end{array}$} & affirmative: & $\begin{array}{l}\text { Ar + verb + subject }+ \text { object }_{1}+\text { object }_{2} \\
\text { Ar ól tú fuisce nó caife? } \\
\text { Did you drink whiskey or coffee? }\end{array}$ & Alternative question \\
\hline & negative & $\begin{array}{l}\text { Nár + verb + subject + object } \\
\text { Nár ól tú fuisce? } \\
\text { Didn't you drink whiskey? }\end{array}$ & Polar question \\
\hline
\end{tabular}

Present/Future
an
ni/chan
gur / gurb

Table 1: The appropriate question particle

Table 2: The morphosyntax of the question particle

\begin{tabular}{lllll}
\hline Tense & Affirmative particle & Lenition/Eclipsis $^{3}$ & Negative particle & Lenition/Eclipsis \\
\hline Present & an & $\mathrm{E}$ & nach & $\mathrm{E}$ \\
Past/preterit & ar & $\mathrm{L}$ & nár & $\mathrm{L}$ \\
\hline
\end{tabular}

3 Lenition, (called séimhiú in Irish) is an initial mutation that affects the spelling and pronunciation of words that begin with the letters $b, c, d, f, g, m, p, s$ and $t$. The word meaning does not change. Lenition is represented in written text with a letter $h$ placed after the first letter of a word. Lenition is also referred to as aspiration. (Source: http://www.nualeargais.ie/gnag/lenition.htm).

Eclipsis, also known as nasalisation, is the substitution of the unvoiced consonants with the corresponding voiced ones ( $c$ becomes $g$, $f$ becomes $b h, t$ becomes $d$, $p$ becomes b). Voiced consonants are then replaced with nasals ( $b$ becomes $m, d$ becomes $n, g$ becomes $n g$ ). 
We are interested in the interrogative form. While the question particle an is used as an alternate or polar question marker ${ }^{4}$, the particle an can be used to support a variety of simple queries (6).

(6)
Introducing a simple query
a. Ar chuir tú isteach air?
QPST put.PST 2SG in on+3SG
Did you apply for it?
b. An ndéanfaidh siad é?
$Q$ do.FUT 3PL 3SG.M.ACC
Will they do it?
c. Ar bhuail sé é?
QPST hit 3SG.M.NOM 3SG.M.ACC
Did he hit him?
d. An dochtúir é?
QCOP doctor 3SG.M.ACC
Is he a doctor?
e. An leatsa an carr sin?
QCOP with+2sG det car that
Do you own that car?
f. An fear mór a bhí ann?
QCOP man big REL be.PST there
Was he a big man?
g. Ar fada go mbeidh deiread leób?
QCOP long that be.FUT end with+3PL
Will it be long before there's an end to them?

\section{The alternative questions of Irish}

Alternative questions are similar in many ways to polar yes-no questions, but also have important differences as we will see. A major difference is that alternative questions do not, under any circumstances, allow for yes-no answers. Alternative questions are constructed in such a way that the licenced answer cannot be yes, or no. Instead, an appropriate answer must contain one of a selection from the alternative choice options listed in the framing of the question. Alternative questions are dependent on the presence of disjunction. Consequently, the set of alternative propositions framed within the question is equal to the set of possible

\begin{tabular}{cccccc}
\hline consonant & eclipsed & spoken & consonant & eclipsed & spoken \\
\hline$b$ & $m b$ & {$[\mathrm{~m}]$} & $g$ & $n g$ & {$[\mathrm{ng}]$} \\
$c$ & $g c$ & {$[\mathrm{~g}]$} & $p$ & $b p$ & {$[\mathrm{~b}]$} \\
$d$ & $n d$ & {$[\mathrm{n}]$} & $t$ & $d t$ & {$[\mathrm{~d}]$} \\
$f$ & $b h f$ & {$[\mathrm{v}] /[\mathrm{w}]$} & & & \\
\hline
\end{tabular}

(Source: http://www.nualeargais.ie/gnag/eklipse.htm)

4 Data is used from the websites:

https://en.wikipedia.org/wiki/Irish_conjugation\#Interrogative_particles, https://www.teanglann.ie/ga/, https://www.gaois.ie/en/corpora/monolingual/, http://www.nualeargais.ie/gnag/kopul1.htm.

Scholarly works consulted include: An caighdeán oifigiuil 2017; Bennett, et al. 2015; Christian Brothers 1997; de Bhaldraithe 1987; Collins Irish Grammar 2011. Doherty 1996; Doyle 2001; McCloskey 1991; McGonagle 1991; Ó Dónaill 1981; Ó Mianáin 2020, Ó Sé 1990; Ó Siadhail 1989, Ward 1974. 
answers defined in virtue of the form of the question. A primary quality of alternative questions then is that they typically only allow felicitous answers which choose one out of the set of alternatives listed in the question (or by declaring a lack of interest to any of the listed alternatives). That is, alternative questions list the set of alternatives as option-1, option-2, and so on, within the formulation of the question. Specifically, in the alternative question, the allowed alternatives are explicitly stated within the question clause. These alternative questions of Irish typically take the schematic format in (7).

(7) Alternative question format

an $\quad \ldots \quad N P_{X}$ nó $\quad \mathrm{NPY}_{\mathrm{Y}}$

QPRT $\ldots . . \mathrm{X}$ or $\mathrm{Y}$

The alternative question (8) posed by the speaker is used to determine which of the two (or possibly more) specific alternatives holds for the addressee. The alternative question may be posed in different ways but the format of the answer remains the same. In alternative questions, a set of alternatives is proposed by the question and a selection from these is requested from the interlocutor (9) by way of a response. Before the question is answered, $S$ is unclear as to whether $\mathrm{H}$ wants option-1 or option-2. For convenience, we label these options as Y1 and Y2. Only one of these is selected by $\mathrm{H}$ within the answer. The logical structure and internal semantics of the alternative question and possible answers is represented in (10-11). The elided elements are flagged in the logical structure representation of the asserted answer - these are in common ground as referents because they were introduced within the question.

Alternative question

(8) a. An fearr leat tae nó caife?

QPRT prefer with:prep+2SG tea or coffee

Do you prefer tea or coffee?

b. An ólann tú tae nó caife?

QPRT drink:PRS 2SG tea or coffee

Do you drink tea or coffee?

Alternative question

(9) a. Q: An ólann tú tae nó caife?

QPRT drink:PRS 2SG tea or coffee

Do you drink tea or coffee?

$\mathrm{P}=$ you drink tea or coffee

Answer 1: Ólaim tae. [Positive response]

drink:V.PRS tea

I drink tea.

Answer 2: Tae.

[Positive response]

Tea.

([I drink $]^{\text {ellipsis }}$ tea.

b. Q: An ólann sí tae nó caife?

QPRT drink:PRS 3SG.F tea or coffee

Does she drink tea or coffee?

$\mathrm{P}=$ she drinks tea or coffee

Answer 1: Ólann sí tae.

drink:V.PRS 3SG.F tea

[Positive response]

She drinks tea. 


$$
\begin{array}{ll}
\text { Answer 2: } & \text { Tae. } \\
& \text { Tea. } \\
& \left([\text { she drinks }]^{\text {ellipsis}}\right) \text { tea. }
\end{array}
$$

As a response to the question, the answer is a speech act of assertion. The logical structure of the alternative question and answer is indicated in (10); the $\mathrm{X}$ argument is not spoken, it is elided, but is retrievable from context. The semantics of the question is indicated in (11). Neither the verbal predicate nor the $\mathrm{X}$ argument is spoken, both are elided, but again retrievable from context. With alternative questions, the disjunctive set of possible responses is constrained by the list of alternative options that are specifically listed in the question. The hearer picks one of these options in the construction of the answer.

(10) Logical structure of the alternative question and answer

$$
\begin{aligned}
& \text { a. Q.Alternative [do' } \left.\left(x, \operatorname{pred}^{\prime}(x, y 1 \vee y 2)\right)\right] \\
& \text { b. [assert' } \left.\left(\text { do' }^{\prime}\left(\mathrm{x}, \operatorname{prred}^{\prime}(\mathrm{x}, \mathrm{y} 1)\right)\right)\right] \\
& \text { c. } \quad\left[\operatorname{assert}^{\prime}\left(\mathbf{d o}^{\prime}\left(\mathrm{x}^{\text {ellipsis }}, \text { pred }^{\text {ellipsis' }}\left(\mathrm{x}^{\text {ellipsis }}, \mathrm{y} 1\right)\right)\right)\right]
\end{aligned}
$$

(11) Semantics: Question' (P=you drink tea or coffee, tea $\mid$ coffee) context before question

S: know' (p, ?)

context after answer

S: Bel' (p, tea) or S: Bel' (p, coffee)

$S:$ know' (p, tea) or S: know' (p, coffee)

Subject to pragmatic context, there is a reading of an alternative question that licences a polar question interpretation (12). In this context, the [tae nó caife $]_{\mathrm{np}}$ is viewed as a single complex NP rather than a list of choices. In addition, it is possible to view the alternative question as a disjunction of two (or more) polar questions (13). In this view, in the second disjunct, the question particle, verbal predicate and subject argument are all elided in the syntactic realisation.

(12) a. Alternative Q:

b. Polar Q:

An ólann tú $[\text { tae }]_{\mathrm{np}}$ nó $[\text { caife }]_{\mathrm{np}}$ ?
An ólann tú $[$ tae nó
QPRT drife $]_{\mathrm{np}}$ ?
Do you drink [tea or coffee]?
$\mathrm{P}=$ you drink [tea or coffee] $\mid \neg \mathrm{p}$

(13)

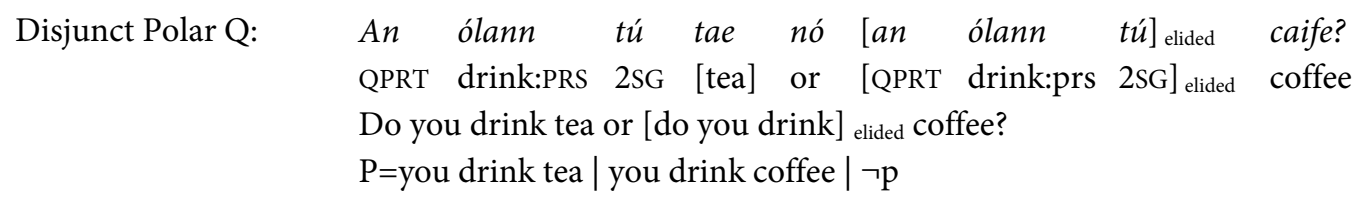

We therefore have two perspectives on the nature of the alternative question form. In the first view, we can treat the alternative question as a distinct interrogative form containing a list of options (two or more) from which the addressee, in their answer, must make a single selection. In the second view, we can consider the alternative question as a realisation of the polar question but reflecting disjunction across two (or more) clauses within the sentence. Ellipsis occurs in 
the second clause. Here, the negative proposition is an implicit 'option'. This second view considers the alternative question form as underlyingly disjoined polar questions.

With alternative questions:

a. A specific question particle is used.

b. A specific syntactic form is employed with alternative questions.

c. The alternative question form contains a list of options such that the answer must select from one of these.

d. The alternative question form may involve instances of ellipsis.

e. The answer to an alternative question contains ellipsis of the material following the verb.

f. The answer to an alternative question may optionally contain ellipsis of the verbal predicate as well as the subject argument.

g. The alternative question form can be viewed as a realisation of two (or more) disjunct polar questions.

We now proceed, in the next section, to examine polar yes-no questions of Irish.

\section{The polar yes-no question as an interrogative sentence}

We have considered alternative questions as an interrogative form where a set of alternatives is proposed and a selection from amongst those is requested from the interlocutor. In contrast, polar yes-no questions denote a set consisting of a proposition and its negation and request confirmation or negation of the proposition. Polar yes-no questions are typically used to inquire about the truth or falsity of the proposition they express. As well as a positive confirmation or negative type answer, answers to polar questions can, of course, typically also assume any value on a scale between 'true' and 'false', as, for example, 'maybe', 'I don't know', 'perhaps', 'possibly', and other such responses.

Essentially, a polar question has a set of two propositions, $\mathrm{p}$ and $\neg \mathrm{p}$, but frames just one of these, $\mathrm{p}$, in the question. The $\neg \mathrm{p}$ option is implicit and salient but not syntactically stated. A polar question cannot denote a singleton set and the negative proposition is always (implicitly) available. There are two syntactic constructional forms (14) and (15) for the polar yes-no question, the first form has a matrix lexical verb while the second being a copula form. Across both forms of polar yes-no questions, the morphosyntax requires the clausal form to have the question particle at the front of the clause.

[Polar question - lexical verb form]

$$
\begin{array}{lll}
\text { Q: } & \text { An ólann sé tae? } \\
\text { QPRT drink:V.PRS } & \text { 3SG.M tea } & \\
\text { Does he drink tea? } & & \\
\text { Proposition: } & {[\mathrm{p}=\text { he drinks tea }]} \\
& \text { Negative of Proposition: } & {[\neg \mathrm{p}=\text { he does not drink tea }]}
\end{array}
$$




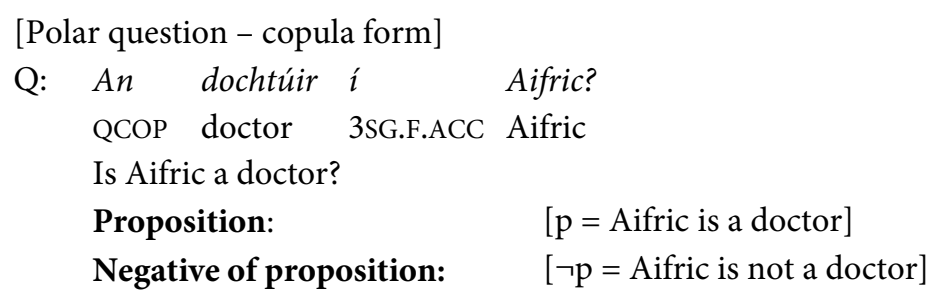

A feature of the polar yes-no question is that it can be biased towards a particular polarity, positive or a negative, within the answer. This happens through the use of forms such as 'someone', for example, within the question, which bias the question towards a positive orientation, as in (16).

(16) Q: Ar thug éinne cuairt aréir?
QPST give.V.PST anyone visit last night
Lit: Did anyone give a visit last night?
Did anyone visit last night?
Proposition: $\quad[\mathrm{p}=$ someone visited last night

This indicates that the speaker believes that the answer is positive and is seeking confirmation. A polar yes-no question specifically favours the core proposition framed by the question. This is the property of polar questions that makes them amenable to a yes-no response. Polar questions therefore make salient the affirmative, along with the implicit negative version of a proposition. The truth-conditional aspect of the meaning of a polar question is simply the set of the truth-conditional meanings of the possible answers to the question. Pragmatically, however, a polar question may also reveal information about the speaker's bias towards a particular answer. The speakers' bias may be with regard to evidence present in the conversational context, that is, an evidential bias. Any contextual evidence is mutually available to the participants in the discourse situation and typically forms part of the present shared common ground. Evidential bias is about contextual information available to all conversational participants, in the shared common ground and inherently public. In contrast, any epistemic bias that may occur is grounded on the speaker's own private beliefs, and need not be shared by other conversational participants.

Typically, we expect that some contextual evidence influences what the speaker believes. Also, posing a question requires the hearer to identify the questioner's intention. Given the context dependency, the evidential or epistemic bias of a polar question assists the hearer in determining what type of information the questioner is seeking. Specifically, the polar question establishes a relation between the propositional content of the question and the speaker's attitude, and whether the proposition $\mathrm{p}$ is in the speaker's belief set.

The strategy that Irish employs in answers to the first form of the polar yes-no questions (with a lexical verb) is a verb-echo strategy. In many languages (Dryer 2005), yes-no questions are typically answered, not by an affirmative or negative particle, but by echoing the matrix verb of the question for positive answers and echoing the verb of the question plus a negation marker of some kind for negative answers. An affirmative answer is an echo of the matrix lexical verb in the question, while the negative answer is an echo of the matrix lexical verb in the question combined with a sentential negation. 
We can consider the structure of these answers in more detail. Within the answer in Irish to the first form of the polar yes-no questions, the tense-marked verb form is used with an explicit nominal argument (17). When a synthetic verb form is used, a pronominal appears in the grammatical relation of nominative subject within the answer. In the synthetic form, the PN is conflated on the end of the verb as a suffix. Additionally, in negative polarity answers, the negative particle is also used.

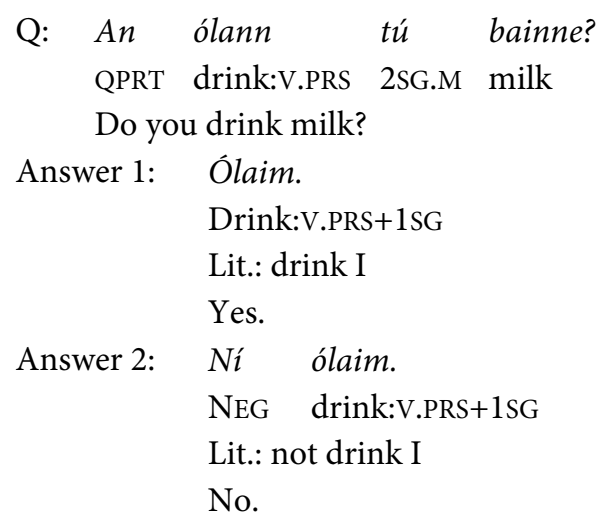

A grammatical subject may be used when the speaker chooses an emphatic affirmation or denial (18 Answer 2, in comparison to 18 Answer 1).

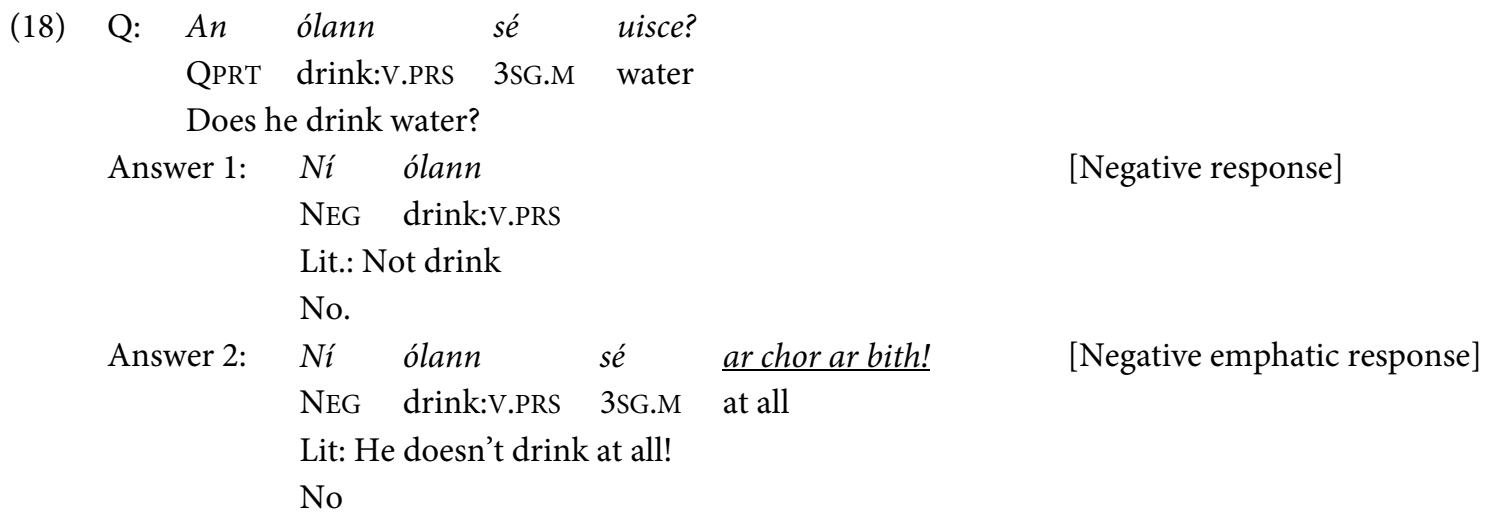

An answer to the first form of the polar yes-no questions can allow for a non-specific response indicating a lack of precise knowledge (19).

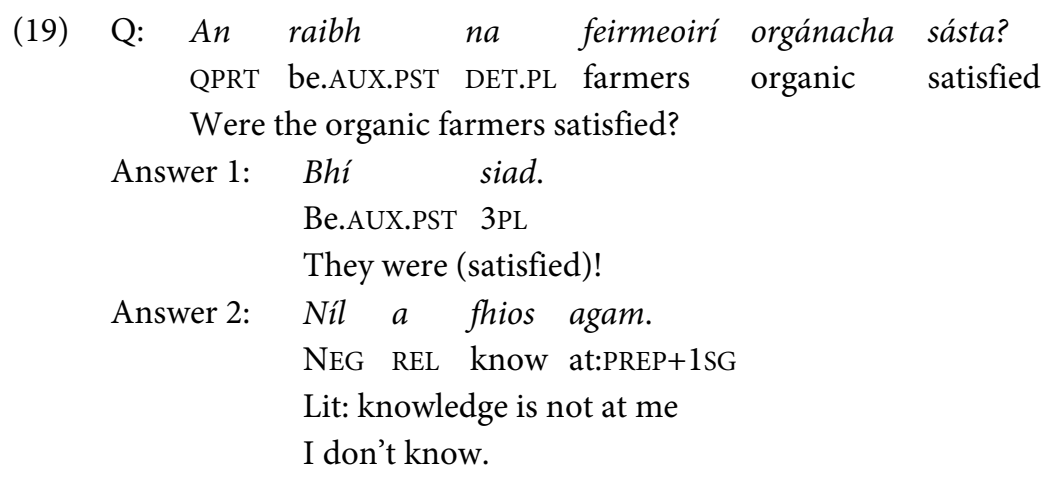

Additionally, a response indicting uncertainty allows elements of the actual question to be embedded in the response (20). 
(20) Q: An mbeidh mórán daoine anseo?

QPRT be.AUX.FUT many people DET+here

Will there be many people here?

Answer: Níl mé cinnte an mbeidh
NEG 1SG certain QPRT be.AUX.FUT
mórán daoine anseo.
many people DET+here
I am not certain how many people will here.

An answer to the first form of a polar yes-no question has several characteristics worthy of note:

a. The lexical verb within the answer is echoed from the question and inflected for tense. As tense is a clausal category that locates the time of the event denoted by a clause in relation to the time of utterance, this is evidence that the answer is a clause.

b. When it occurs in the answer to a polar yes-no question, pronominal subject marking implies the presence of a subject, hence also the presence of a clause.

c. In the answer to a polar yes-no question, ellipsis occurs with respect to the arguments of the verb. Ellipsis can also occur with respect to the verb itself in an alternative question form, as we have seen with example (9).

d. The VSO word order of the answer is maintained and a pronominal constituent is casemarked for the grammatical function of subject in the canonical position post-verb.

e. The context to a polar yes-no question, before the question is answered, has the speaker $\mathrm{S}$ uncertain as to whether the proposition is true, or false. Only one of ( $p \mid \neg \mathrm{p}$ ) holds.

The evidence supports the view that answers to polar yes-no questions have a sentential structure even when they consist of just one pronounced word. The elided material is in common ground and retrieved when needed by the hearer $\mathrm{H}$ for meaning resolution. Specifically, the elided (unpronounced) material is retrieved from the clausal content in the question. A representative example of the logical structure of the first form of the polar question (21) and a typical answer is indicated in (22), with associated semantics is indicated in (23).

Polar question

$\begin{array}{ll}\text { Q: } & \text { An ólann sé bainne? } \\ & \text { QPRT drink:V.PRS 3SG.M milk } \\ & \text { Does he drink milk? } \\ & \text { p=you drink milk | you do not drink milk } \\ \text { Answer 1: } & \text { Ólann. } \\ & \text { drink:V.PRS } \\ & \text { Lit.: drink } \\ & \text { Yes. }\end{array}$

(22) Logical structure of the polar question and answer

a. Q.polar [do' (x, pred'(x, y)]

b. [assert' (do' $\left(\mathbf{x}^{\text {ellipsis }}\right.$, pred' $\left.\left.\left.\left.^{\text {ellipsis }}, \mathbf{y}^{\text {ellipsis }}\right)\right)\right)\right]$

(23) Semantics: Question' ( $P=$ he drinks milk, $\mathrm{p} \mid \neg \mathrm{p})$

context before question

S: $\quad$ Bel' $(\mathrm{p}$, true $\mid$ false $)$

S: $\quad$ know' $(\mathrm{p}, ?)$ 


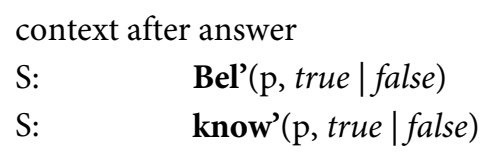

We now briefly look at the second form of the polar question, the copular form (24). An interesting fact of Irish is that the language does not have any exact words which directly correspond to English yes or no and so the language necessarily employs a different strategy where a yes-no answer is required. To formulate an answer to the copula-form polar question, equivalent to a yes or no of English, the copula-derived phrases sea $(c o p+3 s g=$ 'be-it') and ní hea (neg.cop 3sg = 'neg be it') are used. These function as logically equivalent to 'yes' and 'no', respectively. The sea / ní hea can be used in formulating a response to a question with either a $\mathrm{M}$ or F referent (24a vs. 24b). Like the first form of the polar question with the lexical verb, this second form also inquires after the truth value of a proposition.

In these question forms, the copula is used with an interrogative purpose, to elicit information from the partner interlocutor. With an interrogation function, the copula clause uses a different questioning structure for classification vs identification, based on the copula structure indicated in (25). Examples of the copula classification and identification interrogative functions are found in (26) - (27).

(24) a $\mathrm{Q}$ :

[Copula construction]

\begin{tabular}{|c|c|c|c|c|}
\hline (24) & Q: & $\begin{array}{ll}\text { An dochtúir é } \\
\text { QCOP doctor 3sG.M.ACC } \\
\text { Is Lorcan a doctor? }\end{array}$ & $\begin{array}{l}\text { Lorcán? } \\
\text { Lorcan }\end{array}$ & \\
\hline b. & Q: & $\begin{array}{l}\text { An dochtúir i } \\
\text { QCOP doctor 3sG.F.ACC } \\
\text { Is Aisling a doctor? }\end{array}$ & $\begin{array}{l}\text { Aisling? } \\
\text { Aisling }\end{array}$ & \\
\hline & Answer 1: & $\begin{array}{l}\text { Sea. }\left(=\text { is }_{\text {cop }}+\text { ea }_{3 s g . n e u t}\right) \\
\text { COP+3SG.NEUT } \\
\text { Lit: Be (s)he. } \\
\text { Yes. }\end{array}$ & & [Positive response] \\
\hline & Answer 2: & $\begin{array}{l}\text { Ní hea. } \\
\text { NEGCOP 3SG.NEUT } \\
\text { Lit: Not be (s)he. } \\
\text { No. }\end{array}$ & & [Negative response] \\
\hline
\end{tabular}

(25) The general structure of the Irish Copula clause

a) Classification: cop $\underline{\text { Predicate Subject }}$

b) Classification: cop Predicate $_{\text {part-1 }}$ Subject Predicate $_{\text {part-2 }}$

c) Identification: cop Predicate Subject ${ }_{1}$

d) Ownership Identity: cop [Preposition le 'with' + NP $]_{\text {Predicate }}$ Subject

e) Emphasis: cop Predicate Subject

Where

Predicate $_{\text {part-2 }}$ may contain a relative clause

Subject ${ }_{1}$ may be either $[\mathrm{NP}]$ or [NP + a relative clause]

Copula sentences are essentially equational units which establish an identity between a known or presupposed piece of information or entity, and a focused entity that presents new information of some kind. The copula of Modern Irish, as a marked focusing construction that 
brings particular terms into focus, is examined in Nolan (2012: 192-217). These terms may be an NP, an adverb, an adjective, an adposition or other constituent including the verb. The copula predicate contains the new focused information and the copula subject contains the given topic. Whenever a speaker delivers an utterance in a particular context it is done with communicative intent, and the addressee must be able to unpack the utterance given the shared context.

A speaker has to distinguish three facets of knowledge with respect to the hearer of the utterance: a) That which is computable from the physical context; b) That which is available from what has already been said; c) That which is available from common ground knowledge. In an identifying copula, which takes the generalised schematic form:[x is $y]$, the identifying expression in focus is the ' $\mathrm{x}$ ', and this is most likely to be definite $([\operatorname{def}+])$. The ' $y$ ' term is the topic of the construction and represents the entity or information already available to the addressee. With the alternative and polar question forms, the copula is used with an interrogative purpose.

Typically, the classification copula sentence (with copula + indefinite noun + pronoun) will require an indefinite noun while the copula in the identification function (with copula + pronoun/definite noun + pronoun/definite noun) will have a subject that is both specific and definite (Ó Siadhail 1991:224-225). The Collins Irish Grammar (2011:114-115) informs us that an changes to ar for past tense and lenites/aspirates the predicate, but does not change before vowels. In turn, ar correspondingly changes to $a r b h$ for past tense before the pronouns $e ́, i$ and iad. The negative forms apply here also (identification: nach-> nár, classification: nach-> nárbh).

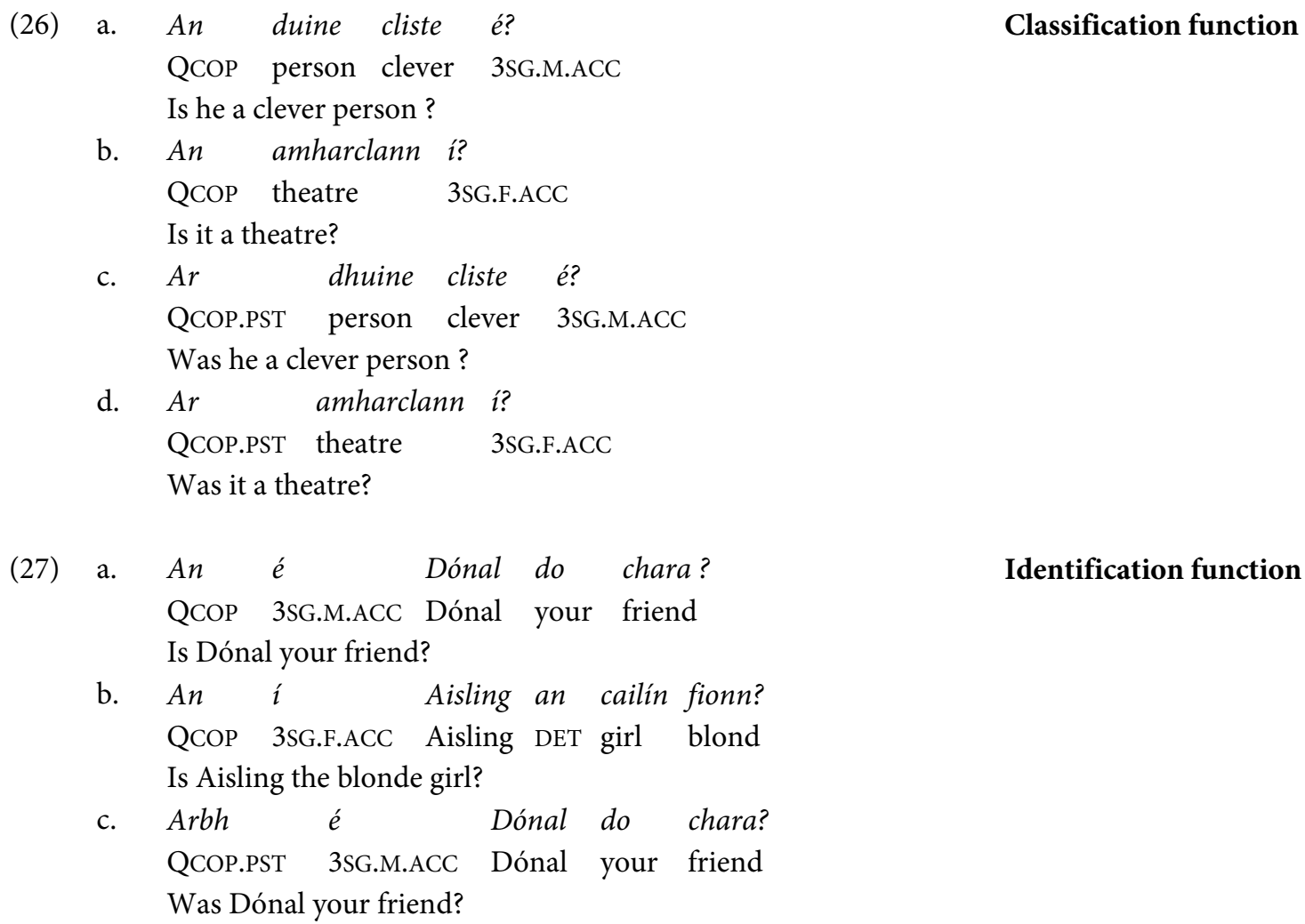


We now briefly consider the rhetorical polar yes-no question. The function of polar questions is to elicit confirmation. Some polar yes-no questions have a rhetorical force (28) that arises when conditions supporting the felicitous use of the speech act of questioning are not met. These questions do not seem to expect a positive or negative answer and are rhetorical in nature. Indeed, responses to the rhetorical polar questions would go against common ground knowledge.

(28) Ní féidir leat mo cheist a fhreagairt, an féidir?

$\mathrm{Ni}$ féidir leat mo cheist a fhreagairt, an féidir?

NEG able with:prep+2SG my question REL answer, QPRT able

You can't answer my question, can you?

Rhetorical polar yes-no questions are actually a particular kind of information seeking questions that masquerade as a polar form but they do not facilitate a yes or no answer. They contain cues from syntax and context which alerts us that the speaker is taking a rhetorical stance.

\section{Concluding discussion}

Irish has clausal types with a specific syntax for requesting information through alternative and polar yes-no questions, like other languages of the world (Haspelmath, Dryer, Gill, and Comrie 2005; Dryer 2005). Asking questions is a core human activity central to communication and understanding. The construction and maintenance of common ground through questioning facilitates the construction of meaning between the interlocutors.

Alternative questions do not inquire about the truth value of a proposition, but rather ask which listed option among a selection of alternatives is most appropriate in a given context. With an alternative question, knowing the meaning of the question is knowing its possible answer. Polar questions do not overtly provide a selection of answer possibilities in either of the forms found in Irish.

With alternative questions we found that:

a. A specific question particle is used.

b. A specific syntactic form is employed with alternative questions.

c. The alternative question form contains a list of options such that the answer must select from one of these.

d. The alternative question form may involve instances of ellipsis.

e. The answer to an alternative question contains ellipsis of the material following the verb.

f. The answer to an alternative question may optionally contain ellipsis of the verbal predicate as well as the subject argument.

g. The alternative question form can be viewed as a realisation of two (or more) disjunct polar questions.

The polar yes-no question is a disjunction of $\mathrm{p}$ and $\neg \mathrm{p}$. The purpose of the polar question is about confirming the truth value of a proposition. It is also about managing the belief status 
of knowledge in common ground. It also updates the information gap in the speaker's common ground from information provided within the answer. Common ground acts as a kind of decentralised knowledge system supporting the cognitive activation of relevant contextual knowledge. Context contributes to the meaning resolution, and to the resolution of any evidential or epistemic bias that may exist.

The answers to polar yes-no questions of Irish contain instances of ellipsis and, as such, represent full clausal expressions with a complete semantics where the elided elements are from the question part of the question-answer pair. To formulate an answer to the first form of the polar yes-no question, the grammar of Irish uses a verb-echo strategy whereby the matrix verb of the polar yes-no question is used in the answer. Nominal argument ellipsis of one or two arguments also occurs. The success of this strategy requires the construction and maintenance of common ground for the retrieval of elided arguments.

We found that the answer to the first form of a polar yes-no question has several significant characteristics:

a. The lexical verb within the answer is echoed from the question and inflected for tense. As tense is a clausal category that locates the time of the event denoted by a clause in relation to the time of utterance, this is evidence that the answer is a clause.

b. When it occurs in the answer to a polar yes-no question, pronominal subject marking implies the presence of a subject, hence also the presence of a clause.

c. In the answer to a polar yes-no question, ellipsis occurs with respect to the arguments of the verb, but not the verb itself.

d. The VSO word order of the answer is maintained and a pronominal constituent is casemarked for the grammatical function of subject in the canonical position post-verb.

e. The context to a polar yes-no question, before the question is answered, has the speaker $\mathrm{S}$ uncertain as to whether the proposition is true, or false. Only one of ( $\mathrm{p} \mid \neg \mathrm{p}$ ) holds.

The evidence is that the propositional content in a question-answer interaction is inferred from the context, specifically from the question with which the answer is paired.

\section{References}

An caighdeán oifigiuil. 2017. Gramadach na Gaeilge: An caighdeán oifigiuil, an dara cló. Dublin: Seirbhís Thithe an Oireachtais. Available at https://data.oireachtas.ie/ie/oireachtas/caighdeanOifigiul/2017/2017-08-03_ancaighdean-oifigiuil-2017_en.pdf. (29 Sept 2020)

Bennett, R., Elfner, E., and J. McCloskey. 2015. Prosody, focus and ellipsis in Irish. MS. Available at: https://www.linguisticsociety.org/sites/default/files/04_95.1Bennett.pdf. (29 Sept2020)

Christian Brothers, The. 1997. New Irish grammar. Dublin: C.J. Fallon, Mount Salus Press.

Comer, N. 2011. Collins Irish grammar. Glasgow, UK: Harper Collins Publishers.

Coulthard, M. (ed.). 1992. Advances in spoken discourse analysis. London: Routledge.

Dayal, V. 2018. Questions. Cambridge: Cambridge University Press.

de Bhaldraithe, T. 1987 [1959]. English-Irish dictionary (with terminological additions and corrections). Dublin: An Gúm.

Doherty, C. 1996. Clausal structure and the Modern Irish copula. Natural Language \& Linguistic Theory 14(1): 146.

Doyle, A. 2001. Irish. Languages of the World/Materials Series. Muenchen: LINCOM Europa. 
Dryer, M. S. 2005. Polar questions. In M. Haspelmath., M. S. Dryer, D. Gill, and B. Comrie (eds.), The world atlas of language structures, 470-473.Oxford: Oxford University Press.

Grice, H. P. 1957. Meaning. Philosophical Review 66, 377-388. Reprinted in P. F. Strawson (ed.). Philosophical logic. London, 1967.

Grice, H. P. 1969. Utterer's meaning and intentions. Philosophical Review 78: 147-177. Reprinted in Grice, H. P. 1975. Logic and conversation. Syntax and Semantics 3: Speech Acts, ed. by Peter Cole and Jerry L. Morgan. 41-58. New York: Academic Press.

Grice, H. P. 1986. Studies in the Way of Words. Cambridge MA: Harvard University Press.

Hamblin, C. L. 1973. Questions in Montague English. Language 10(1): 41-53.

Holmberg, A. 2015. The syntax of yes and no. Oxford: Oxford University Press.

Kecskes, I. and F. Zhang. 2009. Activating, seeking, and creating common ground: A socio-cognitive approach. Pragmatics \& Cognition 17(2): 331-355.

Malinowski, B. 1944. A scientific theory of culture and other essays. Chapel Hill: The University of North Carolina Press.

McCloskey, J. 1991. Clause structure, ellipsis and proper government in Irish. Lingua 85: 259-302.

McGonagle, N. 1991. Irish grammar: A basic handbook. Indreabhan, Conamara, Galway: Cló Iar-Chonnachta.

Monaghan, J. 1979. The Neo-Firthian tradition and its contribution to general linguistics. Tubingen: Max Niemeyer Verlag.

Nerlich, B. 1990. Change in language: Whitney, Bréal, and Wegener. London and New York: Routledge.

Nerlich, B and D. D. Clarke. 1996. Language, action, and context - The early history of pragmatics in Europe and America, 1780-1930. Amsterdam/Philadelphia: John Benjamins Publishing Company.

Nolan, B. 2008. Modality in RRG: Towards a characterisation using Irish data. In R. Van Valin, (ed.), Investigations of the syntax-semantics-pragmatics interface. Studies in language companion series 105, 147-159. Amsterdam/Philadelphia: John Benjamins Publishing Company.

Nolan, B. 2012. The syntax of Irish: A functional account. Sheffield: Equinox.

Nolan, B. 2013. Constructions as grammatical objects: A case study of the prepositional ditransitive construction in Modern Irish. In B. Nolan and E. Diedrichsen (eds.), Linking Constructions into functional linguistics. Studies in language companion series 145, 143-178.Amsterdam/Philadelphia: John Benjamins Publishing Company.

Nolan, B. 2014. Extending a lexicalist functional grammar through speech acts, constructions and conversational software agents. In B. Nolan and C. Periñán (eds.), Language processing and grammars: The role of functionally oriented computational models. Studies in language companion series 150, 143-164. Amsterdam/Philadelphia: John Benjamins Publishing Company.

Nolan, B. 2017. The syntactic realisation of complex events and complex predicates in situations of Irish. In B. Nolan and E. Diedrichsen (eds.), Argument realisation in complex predicates and complex events. Studies in language companion series 180, 13-41. Amsterdam/Philadelphia: John Benjamins Publishing Company.

Nolan, B. 2019. The role of context and common ground in utterance meaning with assertive and declarative speech acts of Irish. In A. Bondaruk and A. Bloch-Rozmej (eds.). Studies in formal linguistics: Universal patterns and language specific parameters. Berlin: Peter Lang.

Nolan, B. 2019. The forms, functions and pragmatics of Irish polar questions and answers. In B. Nolan, and E. Diedrichsen (eds.). Linguistic perspectives on the construction of meaning and knowledge, 105-136. Newcastle upon Tyne: Cambridge Scholars Publishing.

Nolan, B. [forthcoming]. The syntax, semantics and pragmatics of Irish Information questions. In K. Drabikowska and A. Prażmowska (eds.), Exploring variation in linguistic patterns, 175-196. Lublin: Wydawnictwo KUL.

Nolan, B., and E. Diedrichsen. 2013. Linking Constructions into functional linguistics. Studies in language companion series 145. Amsterdam/Philadelphia: John Benjamins Publishing Company.

Ó Dónaill, N. 1981. Gearrfhochlóir Gaeilge-Béarla. Dublin: An Roinn Oideachais, Oifig an tSoláthair.

Ó Mianáin, P. 2020. Concise English-Irish dictionary (An Foclóir Nua Béarla-Gaeilge). Baile Átha Cliath: An Gúm, Foras na Gaeilge.

Ó Sé, D. 1990. Tense and mood in Irish copula sentences. Ériu 41: 61-75. 
Ó Siadhail, M. 1989. Modern Irish: Grammatical structure and dialectal variation. Cambridge MA: Cambridge University Press.

Stalnaker, R. 1999. Context and content, Oxford: Oxford University Press.

Ward, A. 1974. The grammatical structure of Munster Irish. Ph.D. diss. Trinity College Dublin. 